\title{
INFORMAÇÃO ESTATÍSTICA E CIDADANIA
}

\author{
Marilda Lopes Ginez de LaRa \\ Joice Claudia C. Camargo \\ Silvia Gagliardi Rocha
}

\begin{abstract}
Resumo: A informação pública é dever do Estado e direito da população, constituindo-se em um dos elementos indispensáveis ao exercício pleno da cidadania. Por sua natureza e complexidade, entretanto, nem sempre é facilmente compreendida pelos usuários, razão pela qual deve passar por tratamento informacional que permita melhor apresentação e assimilação.

Palavras-chave: estatística; informação pública; disseminação de informação.

Abstract: The State is responsible for maintaining the public sufficiently informed so that individuals may fully exercise their role as citizens. By its complex nature, however, this information is not always easily understandable, and needs to be formulated and presented in such a way that it can be readily assimilated by those whom it is intended to reach.

Key words: statistics; public information; dissemination of information.
\end{abstract}

A circulação das informações produzidas pelo Estado só bem recentemente deixou de ser restrita às esferas públicas produtoras: no Brasil, os serviços públicos de divulgação da informação começaram a aparecer no final da década de 70, ainda que de forma muito incipiente, com base em critérios mais pragmáticos do que técnico-científicos, conhecendo maior desenvolvimento com o processo de democratização brasileira. De início, a existência desses serviços era restrita aos centros próximos do poder, situação que se modifica gradativamente em razão do uso das novas tecnologias, em particular da Internet.

Na construção desses sistemas a ênfase na tecnologia por diversas vezes prepondera quanto aos critérios de organização da informação, e não é raro verificar que os organismos governamentais demonstram certa resistência em relação às práticas necessárias ao trabalho de produção e organização da informação (Malin, 1998). Resulta daí a sobrevalorização da informática (que deveria ser vista no seu sentido final de ferramenta) em detrimento do tratamento da informação. Esse quadro modifica-se apenas de forma bastante lenta, quando as instituições passam a perceber que a informática sozinha não tem oferecido res- postas adequadas para dar conta dos aspectos de organização e recuperação de conteúdos, acordando, em ritmo menor do que seria desejado, para o uso de tecnologias de informação (e não só de informática).

Analisada como ferramenta, todavia, a importância da informática é inegável. De um lado, ela exige que os processos de organização da informação empíricos sejam explicitados, do que decorre a necessidade de delimitar os passos na organização e análise da informação. De outro, ela coloca à disposição dos organizadores de informação um maior leque de possibilidades de armazenamento e de recuperação da informação.

O desenvolvimento de sistemas públicos de informação governamental, porém, não esbarra apenas em problemas da falta de uma metodologia mais adequada para o tratamento da informação. Enquanto administração pública, as instituições sofrem os efeitos da alternância de poder, dos parâmetros com os quais desenvolvem suas atividades e das diferentes prioridades de cada gestão.

No campo da circulação da informação estatística os reflexos dos fatores apontados não são diferentes. As estruturas organizativas também se ressentem continuamente da alteração de objetivos e metas governamentais. A com- 
plexidade do trabalho de organização e disseminação da informação estatística é agravada pelas conseqüências das alterações advindas da transformação da sociedade contemporânea que se rebatem na formulação do sistema estatístico oficial (Porcaro, 2001). Essas mudanças nem sempre são captadas pelas pesquisas estatísticas em razão dos modelos teórico-conceituais que constituem a base das coletas, problema que se materializa claramente quando da construção de metassistemas de informação (sistemas de organização e recuperação construídos para facilitar o acesso aos sistemas estatísticos ou a dados particulares desses sistemas), porém se refletem nas demandas, mais rapidamente sensíveis às alterações.

A elaboração das estatísticas não é feita em um vácuo conceitual, mas verifica-se que nem todos os dados são concebidos com base no mesmo modelo teórico (Starr apud Porcaro, 2001). Qualquer abordagem sistêmica remete a um modelo e representa uma redução da realidade (Pereira apud Porcaro, 2001) e o uso simultâneo de distintos modelos tem como resultado uma multiplicidade de abordagens e, conseqüentemente, formas diferenciadas de agregação da informação.

Todos esses fatores refletem-se no tratamento dos dados e formatação para sua divulgação nos metassistemas, dificultando a consecução de objetivos de democratização da informação que permitiriam mostrar que a informação estatística, mais do que um dever do Estado, é um direito do cidadão.

\section{O USUÁRIO DA INFORMAÇÃO ESTATÍSTICA}

A constituição de metassistemas de informação estatística direcionados a públicos mais amplos que os convencionais começa pela identificação das características desses usuários e dos problemas relacionados ao estabelecimento de "vínculos de adesão" (Baitello Jr., 1994).

Diferentemente do que ocorre com as informações produzidas pelo Estado que se relacionam a serviços diretos ao cidadão (localização de postos de saúde, forma de obtenção de documentos, recepção de reclamações sobre falta de água, pagamentos de taxas, impostos, etc.), o usuário da informação estatística não é o cidadão comum. Os usuários dos serviços estatais têm demandas muito concretas (e, em geral, individuais), seja para exercer um direito (solicitar uma ligação de água, fazer uma reclamação sobre corte de energia elétrica indevido, etc.), seja para o cumprimento de um dever (renovar o exame médico exigido como requisito para dirigir): caracteriza-se por pro- curar uma informação de natureza utilitária relacionada à satisfação de necessidades básicas. Já a motivação do usuário de informações estatísticas relaciona-se à satisfação de uma necessidade também utilitária, mas, em geral, não individual: sindicatos, associações de classe, organizações não governamentais e empresas procuram informação estatística para poder fazer frente às necessidades coletivas, sejam elas relativas à defesa de seus direitos, seja para o planejamento de sua atuação na sociedade. Apenas uma pequena parcela dos usuários procura informação estatística para reflexão, como é o caso de pesquisadores acadêmicos. A pirâmide de necessidades sugerida por Maslow revela que esse tipo de usuário situa-se em um patamar intermediário ou superior e orienta-se, ou por uma vontade de pertencer ou de garantir sua permanência nos diversos grupos e contextos em que circulam, ou para buscar a auto-realização, exercer a criatividade e a reflexão (Barreto, 1994). Nesse ponto de vista, mais do que garantir a permanência em determinados grupos, esses usuários buscam informações para aumentar a oportunidade de sobrevivência e atuação desses grupos.

$\mathrm{O}$ uso da informação estatística requer um nível de conhecimento prévio que, por motivos sociais, econômicos e culturais, não é generalizado. $\mathrm{O}$ conceito de cidadania, porém, é amplo, e compreende também os indivíduos e grupos que têm demandas mais sofisticadas. Para que o usuário comum chegue a fazer uso desse tipo de informação seria preciso que suas necessidades mais básicas já estivessem satisfeitas, o que extrapola o controle das instituições em particular e se situa nos níveis das políticas públicas mais globais. Observa-se, porém, que mesmo os segmentos da população teoricamente aptos a consumir informação estatística não raras vezes deparam-se com inúmeras dificuldades de acesso que, na maior parte das vezes, são relacionadas às formas como elas são organizadas e divulgadas, ou seja, à ausência de vínculos efetivos de adesão.

Entre os elementos que constam na origem do problema destaca-se o uso de um modelo de mensuração da realidade fortemente centrado no emissor, o que, por si só, já representa uma restrição porque desconsidera o usuário (Lara, 1999). A situação se complica porque esse modelo, por conseqüência das alterações advindas das modificações na estruturação da sociedade, como do processo de democratização, também não é mais considerado pelas próprias instituições como adequado para falar sobre a realidade. $\mathrm{O}$ enfrentamento da demanda, por seu lado, padece da ausência de metodologias aptas a identificar seu perfil e é realiza- 
do ou supondo um usuário potencial, imaginado, ou com base em uma análise reativa, valendo-se de suas dúvidas e solicitações como parâmetro para sua definição.

Os modelos de organização de informações centrados no emissor corroboram a hipótese de que quem detém o poder sobre a administração e distribuição da informação, também o detém na circulação, decidindo quanto à forma de sua distribuição à sociedade. "A gestão dos estoques de informação pode ser tão autoritária quanto as políticas que a orientam" (Barreto, 2000). Embora as instituições, ainda que de forma embrionária questionem o modelo, não há consciência clara e generalizada de que ele está sob suspeita. É possível verificar, entretanto, que a crise derivada já está em curso, pelos reflexos materializados no momento da construção de metassistemas de informação. Esses sistemas que, por natureza, buscam estruturar (ou melhor, reestruturar) amplos universos de informação, têm de enfrentar uma heterogeneidade de recortes, uma multiplicidade de olhares simultâneos: o novo e o velho convivem no mesmo espaço/tempo. A constatação fortalece a hipótese de que as instituições, mesmo sem consciência plena do fato, já não contam com modelo estável, único e orientador, do que decorre que os parâmetros para a construção de metassistemas também devem ser reformulados.

\section{CONSTRUÇÃO DE METASSISTEMAS DE INFORMAÇÃO ESTATÍSTICA}

Construir metassistemas de informação estatística que propiciem melhor circulação e apropriação da informação requer que se compreenda o que é dado estatístico e qual é seu estatuto enquanto modo de representação.

Um dado estatístico é uma forma bruta apenas parcialmente localizada. É o resultado de uma mensuração da realidade, como o registro de um nascimento ou óbito, ou um dado administrativo oriundo de um censo (como, por exemplo, o número de alunos de determinada série). Enquanto dados brutos ou intermediários, os dados estatísticos correspondem a eventos empíricos da realidade social, ainda em estágio preliminar, localizados no espaço e no tempo. Estatísticas públicas nesse estágio compreendem os dados censitários, estimativas e registros administrativos (Jannuzzi, 2001), que são normalmente divulgadas de forma sistêmica com base nas referências do universo e do tempo a que se referem.

Os dados estatísticos são representações (geralmente, mas nem sempre $)^{1}$ numéricas da realidade e que, em sua construção, apóiam-se em interpretações teóricas que modelam a realidade, passando a criar seus próprios modelos tomando-se por base a interpretação do real, configurando, dessa forma, certa visão de mundo (Porcaro, 2001).

$\mathrm{O}$ dado estatístico objeto de divulgação nos metassistemas diferencia-se do microdado, ${ }^{2}$ unidade primeira ainda não sistematizada.

A combinação dos dados brutos ou intermediários gera indicadores sociais que, associados, permitem formular sistemas de indicadores. Os indicadores têm um significado particular que é fruto de escolhas direcionadas na obtenção de um recorte sedimentado em uma proposta teórica e/ou programática. Constituem, também, um recurso metodológico, informando sobre aspectos da realidade (Jannuzzi, 2001).

Dados estatísticos e indicadores são úteis na esfera governamental (para o planejamento, formulação de políticas, monitoramento das condições de vida da população, etc.) e nas esferas privadas (por motivos semelhantes). São instrumentos, também, para o exercício da vigilância das ações do Estado por parte dos cidadãos, já que por eles pode-se avaliar seu desempenho. No entanto, como representam recortes comprometidos com arcabouços teóricos, sua condição de representação deve ser validada no processo de circulação de informações.

A otimização da circulação das informações estatísticas é oportunizada com a Internet, pois ela não só amplia as possibilidades de acesso, como também facilita a captação das necessidades de demanda. As experiências na construção de metassistemas estatísticos são recentes e devem muito de sua viabilização ao uso dessas novas tecnologias hipertextuais.

Com a Internet, altera-se o meio de circulação das informações antes feita pela publicação impressa. A tendência primeiramente verificada com sua utilização foi a de reproduzir, nesse meio, as mesmas formas já utilizadas: não raras vezes os sites de informação estatística colocam a público a sistematização de seus dados na forma de produtos, em geral tabelas construídas, e que têm como princípio uma possibilidade interpretativa, acrescidos de alguns recursos hipertextuais (Lara, 1998).

A divulgação de produtos já formatados condicionam seu uso ao ponto de vista que marca a interpretação institucional. A própria Internet, entretanto, ao permitir a percepção das necessidades dos usuários feita pelo registro de suas críticas, observações e solicitações (sobretudo via e-mails), acaba por demonstrar certo descompasso entre o que é oferecido e o realmente demandado. A ex- 
periência não estaria corroborando a tese de que a oferta acaba criando sua própria demanda.

Essa constatação não invalida a divulgação da produção estatística na forma de produtos, pois esse é o meio de apresentar o resultado analítico-interpretativo e institucional das pesquisas realizadas, mas coloca a necessidade de oferecer, também, dados mais desagregados (ou seja, variáveis), mediante os quais os usuários possam dar forma, eles mesmos, a produtos personalizados desenhados segundo suas necessidades. A proposta seria a de utilizar a Internet como meio de transformar uma disseminação reativa em uma que permitisse, de modo efetivo, contemplar o cidadão como produtor de sentido.

É com esse objetivo que a Fundação Sistema Estadual de Análise de Dados - SEADE tem investido na elaboração de um metassistema de informações que, ainda dando seus primeiros passos, já permite apresentar os reflexos da situação já apontada da convivência de distintos olhares, como também de sua aceitação pelo público. O produto/serviço "Informações dos Municípios Paulistas"3 (anteriormente, São Paulo em Dados) lidera o ranking de consultas do site.

\section{EMBRIÃO DO METASSISTEMA DE INFORMAÇÕES ESTATÍSTICAS DA FUNDAÇÃO SEADE}

Um metassistema de informação constitui um gênero de ferramenta de natureza semântica, uma vez que é via conteúdo, mais do que forma, que se pretende organizar as informações com o objetivo de facilitar a busca. Na Fundação SEADE, o embrião dessa ferramenta vem sendo construído valendo-se de dados sobre os municípios paulistas, e que abrange diversos setores socioeconômicos e demográficos.

Os resultados dessa experiência estão publicados no site da instituição (www.seade.gov.br) por meio do produto/ serviço "Informações sobre os Municípios Paulistas" (São Paulo em Dados). A caracterização produto/serviço aqui realizada é uma imposição do uso de uma mídia mais flexível que, além de permitir a divulgação dos dados produzidos, funciona como meio para que o cidadão valhase dele para construir, a seu modo, a informação.

Trata-se de um produto-piloto que, embora não se caracterize como metassistema no sentido desejado e utilizado neste artigo, permite exibir parte dos problemas relacionados a sua constituição.

O princípio adotado para a construção desse sistema foi o de trabalhar, em uma primeira fase, com dados da forma mais desagregada possível (variáveis), partindo-se do pressuposto que os dados em nível maior de combinação (tabelas) já estão contemplados nos produtos específicos. Não se descarta a necessidade de abranger as tabelas, mas trabalha-se com a hipótese de que variáveis, ou dados em menor nível de ordenação, mais do que tabelas, aumentam as potencialidades de interação ao permitir que o próprio usuário construa suas tabelas.

A consecução desse objetivo conduz à constituição de um banco de dados cuja característica principal deve ser a possibilidade de compatibilização de linguagens e de formas de agregação utilizadas. Um banco de dados integrado solicita uma política global de informação, cuja definição pode-se rebater na organização da própria instituição, já que ela pode tornar evidente a necessidade de comensuração. É natural que, em tempos de crise de modelos, seja necessário compatibilizar pontos de vista nem sempre homogêneos.

Se para uma ação em direção à comensurabilidade as unidades de informação são apenas parte, elas podem ter papel mais efetivo nos processos de re-explicitação conceitual. Em tempos de crise paradigmática, os conceitos que sustentam os recortes passam por processo de revisão, para o que o trabalho documentário e terminológico é fundamental. Dito de outra maneira, na construção de uma metaferramenta, ao procurar por definições que sedimentem a configuração das redes lógico-semânticas de termos, a área de informação incentiva e orienta o trabalho de delimitação, fixação conceitual e terminológica. Além disso, baseado no pressuposto de que as classificações hoje, para dar conta do real, devem contemplar a diversidade e a multiplicidade, a construção de uma metaferramenta deve prever a compatibilização entre linguagens e pontos de vista.

Para que um metassistema de informações funcione, ele precisa, de um lado, ser elaborado de acordo com princípios que permitam estruturar as unidades de representação da informação e, conseqüentemente, constituir um todo integrado e dotado de significação. Por outro lado, é necessário que ele permita o estabelecimento de pontos em comum com seus usuários (vínculos de significação), condição para que ele desempenhe o papel de ponte entre linguagens: a linguagem da instituição e a linguagem do usuário. Dito de outro modo, esse metassistema deve ser, ele próprio, uma linguagem, funcionando ao mesmo tempo como uma proposta de organização e um instrumento de comunicação.

No produto/serviço "Informações sobre os Municípios Paulistas", a proposta adotada para levar à aderência foi 
a proposição de um conjunto de categorias temáticas para reunir as informações. Mediante temas genéricos, as informações que têm características semelhantes são agrupadas, processo que pode solicitar subagrupamentos (subtemas) ou remeter de modo direto a descritores de conteúdo, conforme o volume de informações visado.

A formulação das categorias tem como base o uso institucional (não há como escapar de uma hipótese de organização das informações, mas se prevê, ao mesmo tempo, a necessidade de contemplar outras possibilidades de organização. Por exemplo, o sistema estatístico tradicional classifica como uma informação demográfica um evento de óbito por causa, mas para o usuário essa informação faz sentido enquanto um dado de saúde ou de violência). Uma ferramenta de recuperação deve, portanto, veicular uma proposta de organização, mas contemplar, por meio de um sistema de equivalências ou de relações de associação, outras possibilidades de busca.

A função da organização em categorias (ou temas) e subcategorias (subtemas) é a de criar "enquadramentos", fornecendo uma idéia inicial organizadora (Porto, 1998). Essas hipóteses reguladoras não são uma invenção da área de Ciência da Informação, mas constituem princípios lógicos, semânticos e cognitivos que estão na base de qualquer processo de conhecimento, como condição para o engendramento da inferência. Como observa Porto (1998), o processo interpretativo utiliza atalhos, pontos de vista ou filtros que permitem interpretar o mundo, como mapas orientadores.

As categorias devem ser apenas idéias organizadoras e não instrumentos de regulação excessiva, para o que redes de equivalência e de associação entre os termos são essenciais. A rejeição da leitura padrão que dá forma ao sistema estatístico vigente não significa o abandono de toda regra, mas remete à procura de um sistema organizacional mais flexível (não uma cadeia, como nas classificações tradicionais, mas uma rede ou um rizoma, com vários nós organizativos), apto a permitir uma multiplicidade de pontos de vista e apto a reorganizar-se em face do uso. Essa possibilidade, porém, esbarra com as definições utilizadas no processo de coleta que, ao segmentar segundo um princípio (por exemplo, a classificação tradicional das ocupações), impede contemplar outros recortes.

Com a categorização e subcategorização, oferece-se ao usuário hierarquias que o direcionam aos dados mais específicos, do geral ao particular, que são disponibilizadas via cliques sucessivos. Filtros complementares permitem que ele selecione período e abrangência geográfica das informações. Visando oferecer formas alternativas de acesso, uma vez que as hierarquias são orientadas pelas concepções fornecidas aprioristicamente, faz-se necessário disponibilizar índices alfabético-temáticos que funcionam como reorganizadores de estoques. Subníveis, equivalências e associações não lineares devem integrar esse índice, como forma de não restringir a recuperação de informações à forma das palavras.

Esse metassistema não estaria completo sem a disponibilização de um corpo de definições que respondam pelos recortes adotados. As definições funcionam, em uma ferramenta semântica, como meio para levar à compreensão dos fundamentos das conjunções e disjunções que sustentam a organização das hierarquias adotadas.

\section{COMENTÁRIOS FINAIS}

Com o exposto, pode-se verificar que as dificuldades a serem enfrentadas para a construção de metassistemas de informação estatística não são poucas. As iniciativas para sua construção, mais do que resolver os problemas de organização e recuperação da informação para o cidadão, permitem tornar transparentes as conseqüências da crise paradigmática, reunindo elementos para a discussão de um novo formato do sistema estatístico. Uma solução de continuidade não descarta a necessidade do estabelecimento de uma política de informação, para o que a contribuição do trabalho documentário se relaciona à possibilidade de organização de instrumentos multívocos.

A eficiência desses instrumentos remete à adoção de procedimentos terminológicos para auxiliar a identificação, valendo-se do campo conceitual ora dado, das definições necessárias para estruturar (ou reestruturar) o novo sistema de conceitos, de modo que se responda pelas transformações da sociedade e permita a identificação de vínculos de significação com o cidadão.

Adotar procedimentos terminológicos significa, com a utilização de instrumentos teórico-metodológicos próprios, varrer os sistemas estatísticos à procura dos novos conceitos utilizados ou dos conceitos em formação ou transformação, dos termos freqüentemente utilizados e das formas de uso adotadas pelo cidadão, que não necessariamente coincidem com a linguagem oficial. Significa propor procedimentos de fixação terminológica que dêem conta da forma e do conteúdo conceitual dos termos no nível das instituições, como também criar instrumentos para o registro e identificação das formas de uso efetivo das informações. Disso depende, em última análise, a possibilidade de que a informação estatísti- 
ca se constitua, de modo efetivo, em informação para o exercício da cidadania.

\section{NOTAS}

Artigo elaborado com base no texto apresentado ao XX Congresso Brasileiro de Biblioteconomia, Documentação e Ciência da Informação. Fortaleza, 23-28 jun. 2002.

1. O que se pode observar.

2. A divulgação do microdado envolve problemas de identificação da fonte.

3. O produto/serviço, como está hoje na Internet, ainda não incorpora grande parte das propostas de reorganização apontadas neste artigo.

\section{REFERÊNCIAS BIBLIOGRÁFICAS}

BAITELLO JÚNIOR, N. "A sociedade da informação". São Paulo em Perspectiva. São Paulo, Fundação SEADE, v.8, n.4, out.-dez. 1994, p.19-21.

BARRETO, A.A. "Os agregados de informação: memórias, esquecimento e estoques de informação". DataGramaZero: revista de ciência da informação, v.1, n.3, jun. 2000. Disponível em: $<$ http://www.dgz.org.br>.

. "A questão da informação". São Paulo em Perspectiva. São Paulo, Fundação SEADE, v.8, n.4, out.-dez. 1994, p.3-8.
JANNUZZI, P.M. Indicadores sociais no Brasil. Campinas, Alínea, 2001.

LARA, M.L.G. de. "A arquitetura de sistemas de informações estatísticas na Internet”. São Paulo em Perspectiva. São Paulo, Fundação SEADE, v.12, n.4, out.-dez. 1998, p.99-104.

. Representação e linguagens documentárias: bases teórico-metodológicas. Tese de doutorado. São Paulo, ECA-USP, 1999.

MALIN, A. "O mal-estar brasileiro na sociedade de informação". São Paulo em Perspectiva. São Paulo, Fundação SEADE, v.12, n.4 out./dez. 1998, p.30-5.

PORCARO, R.M. "A informação estatística oficial na sociedade da informação: uma (des)construção". DataGramaZero: revista de ciência da informação, v.2, n.2, abril. Disponível em: $<$ http://www.dgz.org.br>. Acesso em 2001.

PORTO, M.P. "Muito além da informação: mídia, cidadania e o dilema democrático". São Paulo em Perspectiva. São Paulo, Fundação SEADE, v.12, n.4, out.-dez. 1998, p.17-25.

Marilda Lopes Ginez de LaRa: Professora da Escola de Comunicações e Artes da USP, Consultora da Fundação Seade (larama@usp.br).

Joice Claudia C. Camargo: Bibliotecária, Analista da Fundação Seade (jcamargo@seade.gov.br).

Silvia Gagliardi Rocha: Bibliotecária, Analista da Fundação Seade (sigrocha@seade.gov.br). 